\title{
O LIQUIDO CEFALORRAQUIANO INICIAL NAS MENINGENCEFALITES POR CRYPTOCOCCUS NEOFORMANS
}

\author{
João Baptista dos REIS-FILHO (1), Afonso Carlos NEVES (2), Samuel Tau ZYMBERG (3) e
} Roberto de M. Carneiro de OLIVEIRA (4)

\begin{abstract}
RES U M O
A criptococose, conhecida desde 1905, é doença grave, causada pelo Gryptococcus neoformans. Nesta entidade o estudo do líquido cefalorraquiano é muito importante visto que o sistema nervoso está envolvido em $81 \%$ dos casos ${ }^{5}$. O propósito do presente trabalho é o de evidenciar as alterações do líquido cefalorraquiano inicial nas meningencefalites criptocócicas e demonstrar a importância de exame minucioso do líquido cefalorraquiano para o diagnóstico precoce desta doença. O material é constituído por 46 observaçōes de pacientes com diagnóstico de meningencefalite criptocócica. O quadro inflamatório crônico, caracterizado por pleocitose predominantemente linfocitária, hiperproteinorraquia e glicose diminuída foi observado em $54 \%$ das amostras de líquido cefalorraquiano $\mathrm{Em} 69 \%$ dos casos o líquido cefalorraquiano mostrava hipertensão. A glicose estava diminuída em $61 \%$ dos pacientes e a taxa de cloretos em 16\%. Eosinófilos em baixa percentagem foram observados em $48 \%$ dos casos. O criptococo foi identificado no líquido cefalorraquiano de $98 \%$ dos pacientes; é salientada a importância da pesquisa a fresco do fungo pelo método da tinta da China, sempre que uma amostra de líquido cefalorraquiano revelar pleocitose. Esta é uma conduta básica para o diagnóstico precoce da criptococose do sistema nervoso.
\end{abstract}

\section{N T R O D U G $\tilde{A} \mathbf{O}$}

A criptococose é conhecida desde 1905 , quando foi descrita por von Hansemann como afecção do sistema nervoso central. Por longo tempo esta doença foi achado de necrópsia. O primeiro caso descrito no Estado de São Paulo foi observado na cidade de Rio Preto e publicado em 1941 por ALMEIDA \& LACAZ 1; em 1944 o segundo caso foi relatado por AL. MEIDA, LACAZ \& MONTEIRO SALLES ${ }^{2}$. A criptococose, também conhecida com as denominações de blastomicose européia, moléstia de Busse-Buschke e torulose, é doença infec- ciosa do homem, de natureza cosmopolita com evolução subaguda ou crônica, causada por um fungo, o Cryptococcus neoformans (Fig. 1), que mostra pređileção pelo encéfalo e seus envoltórios. Entre as micoses disseminadas do homem, a criptococose é aquela que mais frequentemente compromete o sistema nervoso e, como causa de morte por agentes micóticos ela ocupa o segundo lugar, logo depois da histoplasmose 17. Entre os 220 casos da literatura revistos por CARTON \& MOUNT5 mostravam sofrimento do sistema nervoso 178

Trabalho realizado no Laboratório de Iíquido cefalorraquiano da Disciplina de Neurologia do Departamento de Neurologia e Neurocirurgia da Escola Paulista de Medicina

(1) Professor Adjunto Doutor, Chefe do Setor de LCR e Pesquisador pelo CNPq

(2) Médico em Curso de Aperfeiçoamento em Líquido Cefalorraquiano

(3) Médico Residente em Neurologia

(4) Acadêmico de Medicina 
REIS-PMHO, J. B. dos; NBVES, A. C.: ZYMBERG, 8. T. \& OLIVEIRA, R. de M. C. de - o liquido cetalorraquiano inicial nas meningencefalites por Cryptococeus neoformans. Rev. Inst. Med. trop. São Paule 27:173-178, 1985.

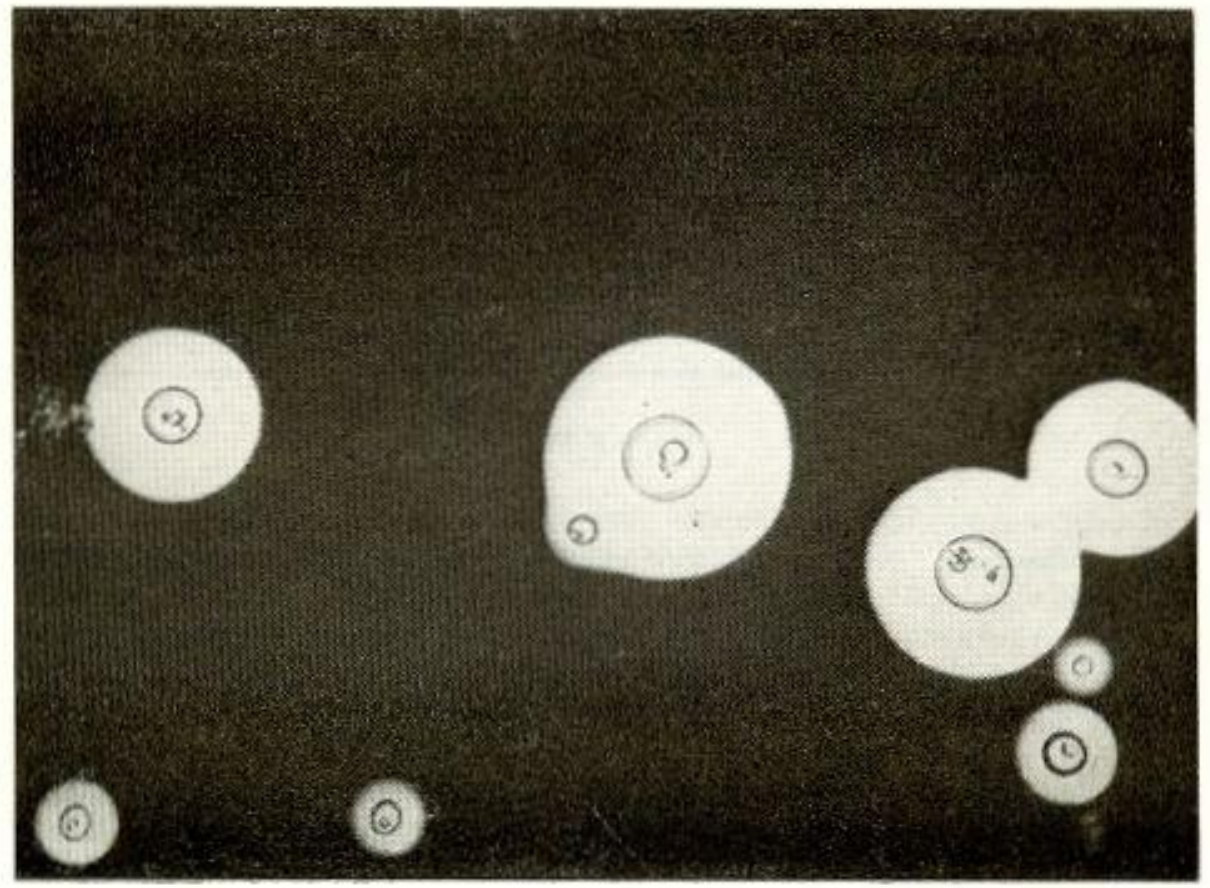

Fig. 1 - Cryptocoecus neotormans. Formas simples e com formaçăo de gémula, $400 \mathrm{X}$

ou seja $81 \%$. Esta afinidade peculiar do criptococo foi atribuida à presença no encéfalo e liquido cefalorraquiano (LCR) de quantidades ótimas de vitaminas e outras substanncias 15 . Enquanto o soro humano normal tem propriedade anticriptocócica ${ }^{12}$, o LCR normal năo tem poder inibidor e é, na verdade, um bom meio nutritivo para o criptococo.

A criptococose é doença grave, de ocorrência relativamente rara, que até $1955 \mathrm{era}$ invariavelmente fatal. Com o aparecimento da anfotericina B, antibiótico de poder fungicida evidente, produzido pelo Streptomyces nodosus, este aspecto modificou-se; sua ação an. ticriptocócica tem sido demonstrada em vá. rios trabalhos 5,9,11. Embora haja numero crescente de comunicaçōes devido ao melhor conhecimento desta entidade, a um estado de alerta constante por parte do médico e a melhores meios de diagnóstico 18,19,24,25, ainda existem muitos casos de diagnóstico tardio ou de necrópsia ". Como esta micose profunda atinge o sistema nervoso em $81 \%$ dos casos 5 a análise do LCR é fundamental para o diag. nóstico de certeza da neurocriptococose.

O propósito do presente trabalho é o de evidenciar as alteraçóes do liquido cefalorra. quiano inicial na meningencefalite criptocócica e, ao mesmo tempo, demonstrar sua importância no diagnóstico precoce desta doença.

\section{MATERIAL E MÉTODO}

O material é constituido por 46 observaçôes de pacientes da Escola Paulista de Medi. cina, com diagnóstico de meningencefalite criptocócica. Năo foram considerados neste estudo os casos de granuloma. A idade destes pacientes variou de 18 a 59 anos, com exceção de 2 casos, 1 com 11 anos e outro com 14; 32 pacientes $(70 \%)$ pertenciam ao sexo masculino e $14(30 \%)$ ao feminino. Para este estudo foi considerada como a $1 . \star$ amostra aquela que permitiu o diagnóstico da meningencefalite criptocócica. Estas observaçōes têm sido coletadas desde 1953; sendo que a partir de 1954 a pesquisa do criptococo a fresco, pelo método da tinta da China, foi praticada em todas as amostras de LCR com pleocitose. Em 44 fichas, dos 46 pacientes deste estudo, os re. sultados dos exames de LCR (24 amostras obtidas por punçắo cisternal e 20 por punçāo do fundo de saco dural) constavam da medida da 
REIS-FILHO, J. B. dos; NEVES, A. C.; ZYMBERG, S. T. \& OLIVEIRA, R. de M. C. de - O líquido cefalorraquiano inicial nas meningencefalites por Cryptococcus neoformans. Rev. Inst. Med. trop. São Paulo 27:173-178, 1985.

pressão inicial, aspecto, contagem global e específica das células, contagem das hemácias quando presentes, taxas de proteínas, cloretos e glicose, reaçóes de fixação de complemento para cisticerco e sífilis. A pesquisa do criptococo a fresco pelo método da tinta da China e o cultivo em meio de Sabouraud foi realizado nas amostras de 45 dos 46 pacientes com meningencefalite criptocócica. Em 2 amostras de LCR foi determinada a taxa de imunoglobulina G. Em 1 paciente o diagnóstico foi feito por autópsia. Em 2 fichas clínicas constava, dos resultados do exame de LCR, apenas aqueles referentes à pesquisa a fresco do criptococo e à prova cultural. Os métodos utilizados para o estudo do LCR e os conceitos de normalidade são os preconizados por REIS \& col. 20 .

\section{RESULTADOS}

A pressão inicial, considerada em apenas 35 pacientes, porque os demais estavam inquietos ou agitados por ocasião da medida, variou de $13 \mathrm{~cm}$ de água a mais de $80 \mathrm{~cm}$ de água. $\operatorname{Em~} 11(31 \%)$ estava normal, discretamente elevada em $2(6 \%)$ e grandemente aumentada em $22(63 \%)$. O LCR, com relação ao aspecto, estava límpido em 6 casos (14\%), opalescente em $31(70 \%)$ e turvo em $7(16 \%)$. O número global das células variou de 9 a 1.050 por $\mathrm{mm}^{3}$; a pleocitose foi moderada no LCR de 12 pacientes $(27 \%)$ e acentuada em 32 $(73 \%)$. A contagem diferencial das células, realizada em 42 amostras de LCR revelou a presença de células linfocitárias em todos os casos, em percentagem que variou de $21 \%$ a $97 \%$, predominando em 39 casos $(93 \%)$; as céIulas monocitóides, também presentes em todos os casos, tiveram a percentagem oscilando entre $3 \%$ e $32 \%$. Os granulócitos neutrófilos, com percentagem entre $0.5 \%$ e $70 \%$, estiveram presentes em 36 casos $(86 \%)$, predominaram em 3 (7\%), com percentagem variando de $59 \%$ a $70 \%$. Os granulócitos eosinófilos com percentagem variando de $0,1 \%$ a $5,0 \%$ estiveram presentes em 20 amostras $(48 \%)$; as células plasmocitárias presentes em 17 casos (40\%), em percentagem oscilando entre $1 \%$ e $9 \%$; os granulócitos basófilos estiveram presentes no LCR de 4 pacientes (9\%), em percentagem que variou de $0,1 \%$ a $2 \%$. A taxa das proteínas totais variou de $23 \mathrm{mg} / 100 \mathrm{ml} \mathrm{a}$
$2.100 \mathrm{mg} / 100 \mathrm{ml}$, estando normal em 6 pacientes $(14 \%)$, discretamente aumentada em 1 (2\%) e acentuadamente aumentada em 37 (84\%). A taxa de glicose oscilou de $5 \mathrm{mg} / 100$ $\mathrm{ml}$ a $110 \mathrm{mg} / 100 \mathrm{ml}$, estando normal ou ligeiramente aumentada em 17 pacientes $(39 \%)$, discretamente diminuída em $7(16 \%)$ e acentuadamente diminuída em $20(45 \%)$. Com relação à taxa de cloretos, esta variou de 608 $\mathrm{mg} / 100 \mathrm{ml}$ a $860 \mathrm{mg} / 100 \mathrm{ml}$, estando normal em 28 casos $(64 \%)$, discretamente diminuída em $7(16 \%)$, grandemente diminuída também em $7(16 \%)$ e acentuadamente aumentada em $2(4 \%)$. A imunoglobulina $\mathrm{G}$ esteve aumentada nos dois casos em que foi dosada, a saber: 18 $\mathrm{mg} / 100 \mathrm{ml}$, correspondentes a $30 \%$ da proteína total em 1 caso e $67 \mathrm{mg} / 100 \mathrm{ml}$, correspondentes a $15 \%$ da proteína total em outro.

Gryptococcus neoformans foi identificado em 44 dos 45 pacientes por meio da pesquisa direta com tinta da China, e naquele em que a pesquisa foi negativa, ele foi isolado pelo cultivo em meio de Sabouraud. Em 1 caso, cujo exame de LCR fez diagnóstico de hemorragia, o diagnóstico foi feito através da autópsia. A contagem de criptococos, realizada em 34 casos, mostrou grande variação: de 0,5 a $19.000 \mathrm{em} 1 \mathrm{~mm} 3$. Em 12 casos (35\%) o número de criptococos por $\mathrm{mm} 3$ era maior que 100 , sendo que em 7 destes casos o aspecto opalescente do LCR era conferido pelo grande número de criptococos e não pelas células. O quadro inflamatório crônico caracterizado por pleocitose predominantemente linfocitária, com hiperproteinorraquia e glicose diminuída foi observado nas amostras de LCR de 24 pacientes $(54 \%)$.

Um resumo dos principais resultados dos exames das amostras de LCR encontram-se no Quadro I.

\section{COMENTÁRIOS}

Neste estudo aproximadamente a metade (54\%) dos pacientes com meningencefalite criptocócica tem alterações do LCR semelhantes àquelas descritas por REIS \& col. ${ }^{21}$ para pacientes com meningencefalite tuberculosa. Esta semelhança pode ocasionar certa dificuldade pa ra o diagnóstico diferencial. Existem porém, algumas diferenças que devem ser analisadas. 
REIS-FILHO, J. B. dos; NEVES, A. C.; ZYMBERG, S. T. \& OLIVEIRA, R. de M. C. de - O líquido cefalorraquiano inicial nas meningencefalites por Cryptococcus neoformans. Rev. Inst. Med. trop. São Paulo 2r:173-178, 1985.

Q U A D R O I

Variações de algumas das provas realizadas nas amostras de LCR

\begin{tabular}{|c|c|c|c|c|}
\hline $\begin{array}{c}\text { Pressãa } \\
\text { inicial }\end{array}$ & $\begin{array}{l}\text { N.o global } \\
\text { de células }\end{array}$ & $\begin{array}{l}\text { Taxa das } \\
\text { proteínas }\end{array}$ & $\begin{array}{c}\text { Taxa de } \\
\text { glicose }\end{array}$ & $\begin{array}{l}\text { Taxa de } \\
\text { cloretos }\end{array}$ \\
\hline
\end{tabular}

\begin{tabular}{lcccccc} 
Condiçäo & \multicolumn{3}{c}{ Pacientes } & $(\%)$ & \\
\hline Normal & 31 & - & 14 & 34 & $\cdots$ \\
Diminuída & - & - & - & 61 & 64 \\
Aumentada & 69 & 100 & 86 & 5 & $\mathbf{5}$ \\
\hline
\end{tabular}

Os resultados desta pesquisa mostram apenas $16 \%$ dos pacientes com taxa de cloretos diminuída, enquanto que em pacientes com menin. gencefalite tuberculosa esta diminuição atinge a maioria dos pacientes 21 ; a glicorraquia que foi encontrada normal ou discretamente aumentada em $39 \%$ dos casos e diminuída em $61 \%$ dos casos de meningencefalite criptocócica deste trabalho, na meningencefalite tuberculosa ela esteve diminuída em $85 \%$ dos casos ${ }^{21}$. A grande diferença porém, das alterações do LCR, entre estas duas entidades, está no estudo bacteriológico. Enquanto que na meningencefalite tuberculosa o bacilo de Koch é encontrado no exame direto em aproximadamente $1 / 3$ dos casos 13,21 e em $66 \%$ dos casos quando considerados $\mathrm{em}$ conjunto a baciloscopia direta, o cultivo e a inoculação em cobaia ${ }^{13}$, no material do presente estudo o criptococo foi identificado em 44 dos 45 casos em que foi pesquisado a fresco, pelo método da tinta da China e em todos os casos quando considerados a pesquisa direta e a prova cultural em meio de Sabouraud. Estes resultados confirmam aqueles de REIS \& col. ${ }^{19}$ baseados no estudo de 8 pacientes. A sensibilidade do método da pesquisa direta pela tinta da China para o achado do criptococo no LCR subaracnóideo foi de $98 \%$ (44 em 45) no material deste estudo; este achado é semelhante aos de outros Autores 6,22. Embora algumas pesquisas clínicas 3,7 e estudos experimentais 23 não mostrem esta elevada sensibilidade, o grande valor para o diagnóstico da meningencefalite criptocócica pela pesquisa direta, com tinta da China, é indiscutível. Esta pesquisa deve ser realizada em todas as amostras de LCR com pleocitose, como preconizado por GIORGI \& col. ${ }^{10}$, independentemente das demais alteraçóes citológicas ou químicas que a amostra apresente. A pesquisa do criptococo a fresco no sedimento de amostra de LCR pelo método da tinta da China, que pela sua simplicidade, rapidez de execução e baixo custo está ao alcance de qual quer laboratório, foi instituída no Laboratório de LCR da Disciplina de Neurologia da Escola Paulista de Medicina em 1954. Esta perseverança permitiu ao Serviço de Neurologia desta Escola, até quanto se saiba, ter hoje a maior experiência latina e talvez mundial, em diagnóstico em vida da meningencefalite por criptococo. Neste periodo, em apenas 1 caso, em que não se fez a pesquisa do criptococo por se tratar de um quadro hemorrágico, o diagnóstico foi feito por autópsia.

Outro fato importante é que o fungo foi demonstrado sempre na primeira amostra em que foi pesquisado. Em apenas 1 caso esta demonstração se deu através do cultivo realizado com material da 6 , amostra de LCR tendo sido a pesquisa a fresco, pelo método da tinta da China, negativa no sedimento de todas as amostras.

As dificuldades de diagnóstico relatadas ${ }^{11}$ se dão provavelmente pela não instituição, pelos laboratórios da pesquisa do criptococo como rotina nas amostras de LCR com hipercitose.

A pesquisa de antígenos e anticorpos através de técnicas sorológicas, embora tenha seu valor diagnóstico ${ }^{14}$, devido à dificuldade de introđução como rotina, deve ser realizada eletivamente. Assim sendo deve ficar reservada àqueles raros casos de meningencefalite de evoIução crônica nos quais, após a instituição de terapêutica antituberculosa, exames seriados de amostras de LCR não revelem melhorias.

Chama a atenção a presença dos granulóci tos eosinófilos nas amostras de LCR de $20 \mathrm{pa}$. cientes. Esta alteração, presente na metade do material, não é citada na literatura provavelmente pela pequena percentagem com que se ajpresenta (Quadro II). Como a mobilização dos granulócitos eosinófilos está relacionada a 
REIS:FILHO, J. B. dos; NEVES, A. C.; ZXMBERG, S. T. \& OLIVEIRA, R. de M. C. de - O líquido cefálorraquiano inicial nas meningencefalites por Cryptococcus neoformans. Rev. Inst. Med. trop. São Paulo 27:173-178, 1985.

fenômenos de defesa do organismo, especialmente em condições de hipersensibilidade 4 , eventualmente a cápsula gelatinosa de polissacarídeo do criptococo é a responsável por este acontecimento.

Q U A D R O II

Incidência dos granulócitos eosinófilos nas amostras de LCR

\begin{tabular}{cc}
$\begin{array}{c}\text { N.o de } \\
\text { pacientes }\end{array}$ & $\begin{array}{c}\text { Eosinófilos } \\
(\%)\end{array}$ \\
\hline 14 & 0,1 a 1,9 \\
5 & 2,0 a 3,9 \\
1 & 4,0 a 5,0 \\
\hline
\end{tabular}

\section{CONCLUSõES}

O estudo do LCR inicial nos casos de me ningencefalite por criptococo permitiu as seguintes conclusões:

1. O quađro crônico, constituído pela associação de pleocitose linfocitária com hiperproteinorraquia e hipoglicorraquia foi observada em $54 \%$ dos pacientes;

2. Pleocitose com predomínio linfocitário foi encontrado em $93 \%$ dos casos e em $7 \%$ houve predominância dos granulócitos neutrófiIos;

3. A pleocitose foi o elemento primordial na indicação da pesquisa direta do criptococo, no sedimento do LCR, pelo método da tinta da China, permitindo o diagnóstico de certeza da neurocriptococose.

\section{SUMMARY}

\section{The CSF in cryptococcal meningitis}

The Authors emphasize the importance of cerebrospinal fluid (CSF) in the diagnoses of nervous system cryptococcosis. It is analysed 46 observations of patients with criptococcal meningitis searched in the $1953-1984$ period, 32 male and 14 female. The age ranged between 11 and 59 years. The cell count of CSF was high as 1050 and as low as 9 per cubic millimeter. The cells were mainly of the mononuclear type. The protein content was normal in $14 \%$ of the cases and increased in $86 \%$. The sugar levels were normal or with a discreet elevation in $39 \%$ and low in $61 \%$. In 45 cases was perform- ed the India Ink test in the CSF sediment and the Cryptococcus neoformans was found in 44 . In this one with India Ink test negative the culture in Sabouraud medium allowed the growth of yeast organism. It is very important to perform the India Ink test in every CSF sample with pleocitosis, in order to make eariy diagnosis. In this paper the spinal fluid change looks like that of tuberculous meningitis in $54 \%$ of the patients. In 7 samples the cloudness of the CSF was given only by the high number of parasites.

\section{REFERENGIAS BIBLIOGRAFICAS}

1. ALMEIDA, F. \& LACAZ, C. S. - Micose pelo "Gryptococcus neoformans". Primeiro caso observado em São Paulo. An. Paul. Med. Cir. (São Paulo) 42: 385-394, 1941.

2. ALMEIDA, F.; LACAZ, C. S. \& SALLES, F. M. Blastomicose do tipo Busse-Buschke (granulomatose criptocócica, Torula infection, Torulosis). Segundo caso observado em $\mathrm{S}$. Paulo. An. Fac. Med. Univ. $\mathbf{S}$. Paulo 20: 115-139, 1944.

3. BUTLER, W. T.; ALLING, D. W.; SPICKARD, A. \& UTZ, J. P. - Diagnostic and prognostic values of clinical and laboratory findings in cryptococcal meningitis: a follow-up study of 40 patients. New Engl. J. Med. 270: 59-67, 1964 .

4. BUTTERWORTH, A. E. \& DAVID, J. R. - Eosinophil function. New Engl. J. Med. 304: 154-156, 1981.

5. CARTON, C. A. \& MOUNT, L. A. - Neurosurgical aspects of cryptococcosis. J. Neurosurg. 8: 143-156, 1951.

6. DE WYTT, C. N.; DICKSON, P. L. \& HOLT, G. W. - Cryptococcal meningitis. A review of 32 years experience. J. Neurol. Sciences 53: 283-292, 1982.

7. EDWARDS, J. M.; SUTHERLAND, J. M. \& TYRER, J. H. - Cryptococcosis of the central nervous system. J. Neurol. Neurosurg. Psychiat. 33: 415-425, 1970.

8. FITZPATRICK, M. J.; RUBIN, H. \& POSER, C. M. The treatment of cryptococcal meningitis with amphotericin B, a new fungicidal agent. Ann. Int. Med. 49: $249-259,1958$

9. GIORGI, D.; PUPO, P. P.; REIS, J. B. \& LIMA, J. G. C. - Tratamento da criptococose do sistema nervoso com a amphotericin B. Arq. Neuro-Psiquiat. (São Paulo) 17: $377-386,1959$.

10. GIORGI, D.; REIS, J. B.; BEI, A. \& REIS-FILHO, J. B. - Criptococose do sistema nervoso central. Arq. Neuro-Psiquiat. (São Paulo) 32: 77-92, 1974.

11. GONÇALVES, A. J. R.; LOPES, P. F. A.; PINTO, A. M. M.; LAZERA, M. ; MENEZES, J. A.; CUNHA, 
REIS-FILHO, J. B. dos; NEVES, A. C.; ZYMBBERG, S. T. \& OLIVEIRA, R. de M. C. de - O. líquido cefalorraquiano inicial nas meningencefalites por Gryptococcus neoformans. Rev. Inst. Med. trop. São Paulo 27:173-178, 1985.

R. Q.; PEREIRA, A. A.; WANKE, B.; BRAGA, M. P.; CLEMENTE, H. A. \& DUARTE, F. - Criptococose: estudo de 27 casos observados no Hospital dos Servidores do Estado - INAMPS e no Hospital Estadual São Sebastião - Rio de Janeiro. J. Bras. Med. 46: $43-63,1984$.

12. IGEL, H. J. \& BOLANDE, R. P. - Humoral defense mechanism in cryptococcosis: substance in normal human serum, saliva and cerebrospinal fluid affecting the growth of Cryptococcus neoformans. J. Infect. Dis. 116: 75-83, 1966.

13. JOOS, H. \& PULVER, W. - Zur Diagnose un Prognose der Meningitis tuberculosa. Schweiz. Med. Wschr. 90: $842-850,1960$.

14. KAUFMAN, L. \& BLUMER, S. - cit. por GONÇLVES, A. J. R. \& col.11

15. LITTMAN, M. L. (1958) - cit. por LITTMAN, M. L. \& col. (1959) ${ }^{16}$.

16. LitTMAaN, M. L. \& SCHEIERSON, S. S. - Gryptococcus neoformans in pigeon excreta in New York City. Amer. J. Hyg. 69: 49-59, 1959.

17. LITTMAN, M. L. \& WALTER, J. E. - Cryptococcosis: Current status. Am. J. Med. 45: 922-932, 1968.

18. LONGO, P. W. \& DINIZ, H. B. - Consideraçōes clínicas sobre a criptococose do sistema nervoso central. Rev. Paul. Med. (São Paulo) 48: 1967, 1956.
19. REIS, J. B. \& BEI, A. - O liquido cefalorraqueano no diagnóstico da criptococose do sistema nervoso. Arq. Neuro-Psiquiat. (São Paulo) 14: 201-212, 1956.

20. REIS, J. B.; BEI, A. \& REIS-FILFO, J. B. - Líquido Cefalorraquiano. São Paulo, Sarvier, 1980; Conceito global de normalidade do LCR, 167-169.

21. REIS, J. B.; GIORGI, D. \& BEI, A. - o líquido cefalorraquiano inicial da meningite tuberculosa. Arq. Neuro-Psiquiat. (São Paulo) 12: 227-235, 1954.

22. RICHARDSON, P. M.; MOHANDAS, A. \& ARUMUGASAMY, N. - Cerebral cryptococcosis in Malaysia. J. Neurol. Neurosurg. Psychiat. 39: 330-337, 1976.

23. SEVERANCE, P. J. \& KAUFFMAN, C. A. - Diagnosis of Cryptococcosis: Comparison of various methods to detect Cryptococcus neoformans. Mykosen 26: 29-33, 1983.

24. TAY, C. H.; CHEW, W. L. S. \& LIM, L. C. Y. Cryptococcal meningitis: its apparent increased incidence in the far east. Brain 95: 825-832, 1972.

25. WALTER, J. E. \& JONES, R. D. - Serodiagnosis of clinical cryptococcosis. Am. Rev. Resp. Dis. 97: 275$282,1968$.

Recebido para publicação em 15/8/1984.

Disciplina de Neurologia da Escola Paulista de Medi. cina

Rua Botucatu, 740. CEP 04023 - São Paulo - Brasil Tel.: $570-4796$ (direto) 